\title{
FLUORESCÊNCIA DE RAIOS X POR DISPERSÃO DE ENERGIA APLICADA À CARACTERIZAÇÃO DE TIJOLOS DE SÍTIOS HISTÓRICOS DE PERNAMBUCO
}

\section{ENERGY DISPERSIVE X-RAY FLUORESCENCE APPLIED TO THE CHARACTERIZATION OF BRICKS OF PERNAMBUCO HISTORICAL SITES}

\author{
Helen Jamil Khoury ${ }^{1}$ \\ hjkhoury@gmail.com \\ Roberto Araújo ${ }^{3}$ \\ robertodaraujo@hotmail.com
}

\author{
Sandra de Brito Barreto ${ }^{2}$ \\ sandradebritobarreto@gmail.com \\ Viviane Khoury Asfora 1 \\ vikhoury@gmail.com
}

\section{RESUMO}

No presente trabalho são 1 apresentados os resultados de estudos por fluorescência de raios $\mathrm{X}$ de tijolos brasileiros. Neste estudo foram avaliados 22 tijolos, sendo sete de Igarassu, dois do Forte do Brum e 13 de Olinda. Um equipamento portátil de fluorescência de raios $X$ por dispersão de energia foi desenvolvido para este estudo. Análises por difração de raios $\mathrm{X}$ também foram efetuadas para determinar as fases cristalinas presentes nos tijolos. Os resultados mostraram a existência de fases minerais, como quartzo, em todos os tijolos avaliados. A Análise da Componente Principal foi aplicada aos dados dos espectros de fluorescência de raios $\mathrm{X}$ obtidos. Os resultados mostraram que a partir do gráfico de scores das componentes principais $\mathrm{CP} 1$ e CP3, respectivamente representadas pelo $\mathrm{Fe}$ e $\mathrm{Ca}$, foi possível separar os tijolos de Igarassu e do Forte do Brum em cinco grupos, que estavam associados com o século de fabricação. Por sua vez, os tijolos de Olinda foram separados em dois grupos, sendo um formado por um único tijolo e o outro grupo pelos demais tijolos. Estes resultados sugerem que os tijolos foram produzidos com diferentes matérias primas ou em diferentes locais.

PALAVRAS-CHAVE: análise não destrutiva, fluorescência de raios $\mathrm{X}$, patrimônio cultural, tijolos, difração de raios X.

\footnotetext{
${ }^{1}$ Departamento de Energia Nuclear, UFPE.

${ }^{2}$ Departamento de Geociências, UFPE.

${ }^{3}$ Departamento de Arquitetura, UFPE.
} 


\begin{abstract}
This work presents the results of X-ray fluorescence analysis of Brazilian bricks, collected from several historical sites of the State of Pernambuco, Brazil. In this study, twenty two bricks were analyzed; seven from Igarassu, two from Forte do Brum in Recife, and thirteen from Olinda. A portable X-ray fluorescence system was assembled and used for the qualitative determination of the chemical elements present in the samples. X-ray diffraction analysis was also carried out to determine the crystal mineral phases in the bricks. All the bricks studied showed several minerals, such as quartz A Principle Component Analysis was applied to the full X-ray fluorescence spectra. In the score plot of principal components $\mathrm{PC} 1$ and $\mathrm{PC} 3$, represented by $\mathrm{Fe}$ and $\mathrm{Ca}$ respectively, it can be seen that the results for the bricks from Igarassu and Forte do Brum may be grouped in five clusters corresponding to the bricks' century and manufacture locations. The analysis of the Olinda bricks yielded two separate groups, one with a single brick and the second group with the other eleven bricks. These results suggest that the bricks were produced with different raw-materials or manufactured in different locations.
\end{abstract}

KEY WORDS: non-destructive analysis, X-ray fluorescence, cultural heritage, bricks, $\mathrm{X}$-ray diffraction.

\title{
CONTEXTO DA PESQUISA
}

O patrimônio cultural é o conjunto de bens com valores reconhecidos por toda a humanidade. É dividido, inicialmente, em duas categorias: os bens intangíveis e os bens tangíveis. A conservação e a restauração atuam sobre o segundo grupo, que é ainda subdividido em bens móveis e imóveis, tais como castelos, igrejas, casas, praças, locais dotados de expressivo valor para a história, arqueologia e ciência em geral.

A preservação do patrimônio cultural tem importância fundamental para o desenvolvimento e enriquecimento cultural de um povo. Os bens culturais guardam informações, registros da história humana, das crenças, dos costumes, do 
conhecimento tecnológico, das condições sociais, econômicas e políticas de um grupo em determinada época.

A conservação do patrimônio cultural inclui, além dos cuidados com o ambiente, o tratamento dos elementos físicos estruturais do objeto, visando adiar os processos de deterioração. A restauração, por outro lado, inclui todos os procedimentos de conservação e ainda atua nos valores históricos e estéticos do patrimônio cultural. Antigamente a restauração era praticada de forma empírica, enquanto que atualmente busca-se intervir o menos possível nas obras, fazendo uso de aparatos técnico-científicos que conferem uma base segura para as intervenções. É uma atividade multidisciplinar que envolve físicos, químicos, historiadores, arqueólogos, restauradores e outros especialistas, para desenvolver e aplicar várias técnicas de análise que servirão de base à restauração do patrimônio.

Dentre essas diversas técnicas analíticas, a ênfase deste trabalho encontra-se nos métodos de análise elementar não destrutiva, mais precisamente na fluorescência de raios X. A fluorescência de raios X (FRX ou XRF, do inglês X-Ray Fluorescence) é uma técnica não destrutiva baseada na medida da intensidade dos raios $\mathrm{X}$ característicos emitidos pelos elementos químicos constituintes da amostra. Através desta técnica pode ser feita uma análise qualitativa e também quantitativa sobre a constituição da matéria, permitindo determinar a composição química sem haver sua destruição total ou parcial. Devido a essas características, ela vem sendo bastante utilizada em estudos do patrimônio cultural. 
Essa técnica, além de beneficiar a conservação e preservação de bens culturais, tais como quadros, afrescos, edificações, pinturas rupestres e obras de arte, também permite a identificação de falsificações e restauros.

Entre as vantagens da fluorescência de raios $\mathrm{X}$ para a análise química de elementos podemos citar: a simplicidade da técnica, a análise rápida e multielementar, a adaptabilidade para automação e a não necessidade de preparação destrutiva da amostra exigida pela maioria dos outros métodos analíticos.

Tendo em vista a importância desta técnica e à existência na UFPE de grupos de pesquisa que atuam na área de Instrumentação Nuclear, Arqueologia e em Patrimônio Cultural, é objetivo deste trabalho implantá-la no DEN / UFPE e aplicá-la na caracterização de tijolos de sítios históricos de Pernambuco.

\section{MATERIAIS E MÉTODOS \\ CARACTERIZAÇÃO DAS AMOSTRAS DE TIJOLOS}

Neste estudo foram analisados 22 tijolos, sendo que 7 eram da região de Igarassu, 2 do Forte do Brum, em Recife, e 13 do sítio arqueológico no Alto da Sé, em Olinda. 


\section{TIJOLOS DE IGARASSU E DO FORTE DO BRUM}

O grupo de 9 tijolos é constituído de tijolos brasileiros e holandeses, encontrados em sítios históricos do Estado de Pernambuco. Destes, dois são do século XVII e foram coletados no Forte do Brum (Recife), um do século XVIII coletado no Convento Santo Antônio em Igarassu e seis foram coletados na Casa da Câmara e Cadeia, em Igarassu, sendo um deles do século XX e os outros cinco do século XIX.

Existe conhecimento da existência de três Casas da Câmara e Cadeia de Igarassu. A primeira foi construída provavelmente entre os anos de 1560 e 1564 em alvenaria de pedra e, ou, tijolos e foi destruída pelos holandeses em 1632 (BARRETO, 1947). No início do século XVIII foi construída em outro local uma nova Casa da Câmara e Cadeia que por falta de manutenção acabou sendo abandonada e demolida no início do século XIX.

Entre 1826 e 1845 as sessões da câmara e as detenções foram realizadas em diversos edifícios. Em 1876 foi construído um novo prédio, em frente à antiga localização do prédio da Casa da Câmara e Cadeia, que foi utilizado até 1935 quando então passou a servir como residência de diversas autoridades instaladas no município (ARAUJO, 2003). Até está data não havia registro de novas alterações, e somente, a partir da década de 50 do século XX foram promovidas grandes reformas, que transformaram sucessivamente o edifício em residência do prefeito, biblioteca pública, galeria de restauração e finalmente fórum da cidade. 
Atualmente o edifício se encontra abandonado, conforme se observa na Figura 11 que mostra fotos da terceira Casa da Câmara e Cadeia desde a década de XX até o ano de 2006.

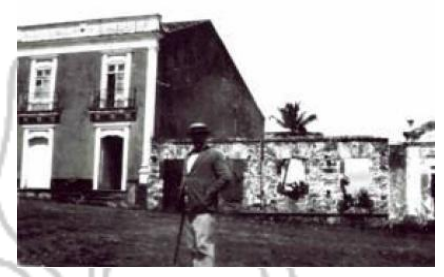

(a)

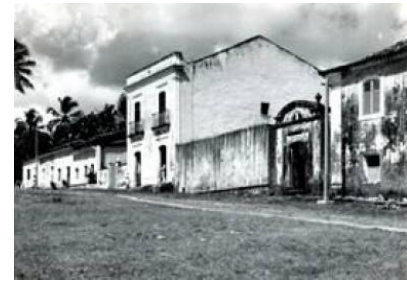

(b)

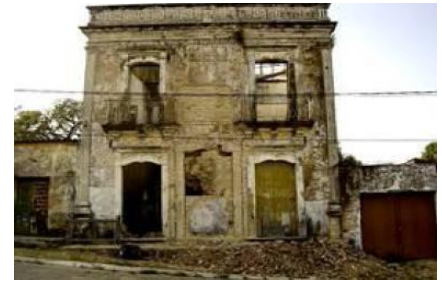

(c)

Figura 11: Fotografia da terceira Casa da Câmara e Cadeia de Igarassu (a) década de 20 ou 30 (b) década de 70 do século XX (c) ano de 2006 (ARAUJO, 2009).

A grande variedade destes tipos de tijolos, não é decorrente apenas das sucessivas intervenções pelas quais o edifício passou, mas, também, da ausência de padronização na sua fabricação. É importante ressaltar que a presença de pedregulhos e de porosidades encontradas é característica de tijolos brasileiros do século XIX.

De fato, os tijolos brasileiros mais antigos foram importados da Europa. No entanto, com o assentamento de pessoas na nova terra, surgiram olarias de fabrico de tijolos. Neste período, não havia mão-de-obra especializada, assim, utilizavamse a mão-de-obra escrava, de modo que os tijolos das primeiras décadas do século XIX apresentaram-se geralmente mal cozidos e porosos e de dimensões avantajadas. Não raro observam-se pedregulhos e matéria orgânica no interior de 
sua massa. Por outro lado, tijolos encontrados nos sítios mais antigos (antes do século XIX), afora diferenças em suas dimensões, apresentam-se como produtos mais sofisticados. Podem ser caracterizados por cozimento mais uniforme e um tratamento cuidadoso da pasta e da argila empregada, possuindo, consequentemente, uma aparência homogênea e melhor resistência (ARAUJO, 2003).

Em outro sítio de Igarassu foi coletado mais um tijolo do Convento de Santo Antônio da Capela dos Terceiros, medindo $18,7 \mathrm{~cm}$ de largura, $6,5 \mathrm{~cm}$ de espessura e 37,0 cm de comprimento. Este tijolo apresenta uma coloração mais escura e maiores dimensões do que os demais tijolos coletados em Igarassu.

\section{TIJOLOS DE OLINDA}

O segundo grupo de tijolos analisados é composto por 13 tijolos retirados de uma recente investigação Arqueológica do Alto da Sé, em Olinda (PE) da cidade antiga do período de Duarte Coelho. Tais escavações foram distribuídas em seis áreas de uma faixa urbana que se estende do pátio da igreja da Sé até as proximidades da Igreja da Misericórdia. Neste sítio foram encontrados vários trechos de vias públicas, fundações, paredes de habitações e estruturas que podem ser muros de contenção ou muralhas

Os tijolos coletados em Olinda são típicos do Período Colonial, e certamente foram moldados em formas simples de madeira e cozidos em fornos intermitentes 
rústicos (fornos de meda). Além disso, não seguem qualquer norma ou padrão, não possuem marcas de seus fabricantes, variam em tamanho e forma, apresentam pasta grosseiramente trabalhada e deformações, isto é, suas superfícies não são planas.

\section{MEDIDAS DE FLUORESCÊNCIA DE RAIOS $X$ NOS TIJOLOS COLETADOS}

A fluorescência de raios $\mathrm{X}$ foi efetuada no centro da superfície cortada do tijolo, onde quatro pontos distintos foram medidos. Na parte externa do tijolo também foi realizada um ponto de medida. Observou-se que devido ao intemperismo, esta medida, realizada na superfície dos tijolos, apresentava uma dispersão muito grande em relação aos outros quatro pontos de medida e por isso foi descartada.

A Figura 29 mostra fotos da localização de um ponto interno de quatro tijolos distintos onde foi realizada uma medida.
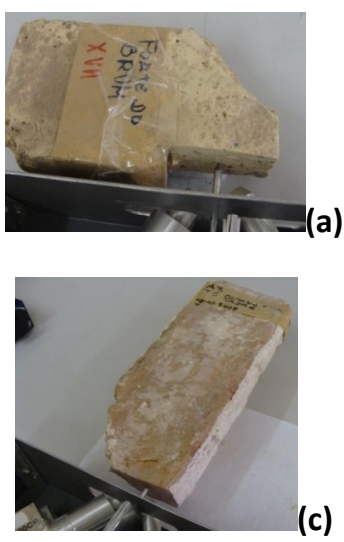
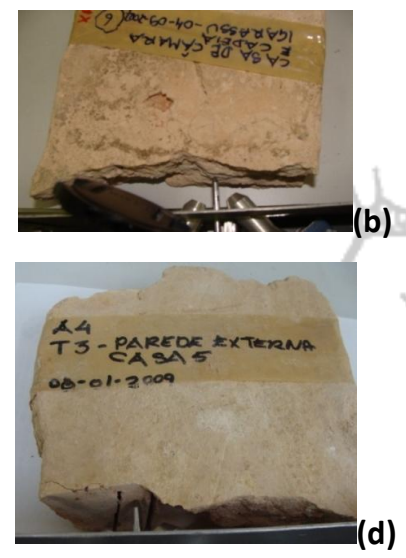

Figura 2: Fotos das medidas de EDXRF realizadas na parte interna dos tijolos (a) YellowBrick (Forte do Brum). (b) Casa da Câmara e Cadeia no 06 (Igarassu); (c) B07 (Olinda); (d) B23 (Olinda). 


\section{DIFRAÇÃO DE RAIOS X}

Para análise de difração de raios X (DRX) foi cortada uma lâmina de $6 \times 4 \mathrm{~cm}^{2}$ de área e $5 \mathrm{~mm}$ de espessura de cada tijolo. Posteriormente cada lâmina foi cominuída utilizando um pistilo e almofariz de ágata, para evitar contaminação. Em seguida, as amostras foram peneiradas para obter-se a granulometria de trabalho entre $100(150 \mu \mathrm{m})$ e 200 mesh $(75 \mu \mathrm{m})$.

Os tijolos de Igarassu foram analisados utilizando um difratômetro SHIMADZU, modelo XRD-6000, com radiação de $\mathrm{CuK}_{\alpha}(\lambda=1.541874 \AA$ ), com um intervalo de varredura de $2^{\circ}$ a $65^{\circ}(2 \theta)$ e com velocidade do goniômetro de $2^{\circ} / \mathrm{min}$. As medidas de difração foram realizadas utilizando uma tensão de $40 \mathrm{kV}$ e corrente de $20 \mathrm{~mA}$.

Os tijolos de Olinda foram analisados com um difratômetro de raios $\mathrm{X}$ da RIGAKU, modelo D/MAX 2200, também com radiação de $\mathrm{CuK}_{\alpha}$, tensão de 40 $\mathrm{kV}$ e corrente de $20 \mathrm{~mA}$, intervalo de varredura entre $10^{\circ}$ e $90^{\circ}(2 \theta)$ e velocidade do goniômetro de $2 \%$ min.

Depois de obtidos os difratogramas, foram identificadas as fases minerais nos respectivos difratogramas com base nos padrões difratométricos da Inorganic Crystal Structure Database (ICSD). 


\section{RESULTADOS E DISCUSSÃO: FLUORESCÊNCIA DE RAIOS X TIJOLOS DE IGARASSU E DO FORTE DO BRUM}

Os resultados das análises de fluorescência de raios $\mathrm{X}$ em quatro pontos da parte interna dos tijolos de Igarassu e Forte do Brum estão apresentados na Figura 2. Com base na curva de calibração foi possível identificar as energias correspondentes aos fotopicos.

A partir dos espectros e dos dados tabelados das energias dos raios $\mathrm{X}$ característicos $\lambda$ da linha $K(E G \& G$ ORTEC, 1980) foi possível identificar os elementos presentes nas amostras analisadas, que estão identificados nos espectros de fluorescência de raios X. Nos espectros também aparecem os fotopicos correspondentes as linhas $\mathrm{L}$ do tungstênio (W), as quais correspondem à radiação proveniente do anodo do tubo de raios $\mathrm{X}$.

\section{DIFRAÇÃO DE RAIOS X}

Para análise de difração de raios X (DRX) foi cortada uma lâmina de $6 \times 4 \mathrm{~cm}^{2}$ de área e $5 \mathrm{~mm}$ de espessura de cada tijolo. Posteriormente cada lâmina foi cominuída utilizando um pistilo e almofariz de ágata, para evitar contaminação. Em seguida, as amostras foram peneiradas para obter-se a granulometria de trabalho entre $100(150 \mu \mathrm{m})$ e 200 mesh $(75 \mu \mathrm{m})$.

Os tijolos de Igarassu foram analisados utilizando um difratômetro SHIMADZU, modelo XRD-6000, com radiação de $\mathrm{CuK}_{\alpha}(\lambda=1.541874 \AA)$, com um intervalo de varredura de $2^{\circ}$ a $65^{\circ}(2 \theta)$ e com velocidade do goniômetro de $2^{\circ} / \mathrm{min}$. As 
medidas de difração foram realizadas utilizando uma tensão de $40 \mathrm{kV}$ e corrente de $20 \mathrm{~mA}$.

Os tijolos de Olinda foram analisados com um difratômetro de raios $\mathrm{X}$ da RIGAKU, modelo D/MAX 2200, também com radiação de $\mathrm{CuK}_{\alpha}$, tensão de 40 $\mathrm{kV}$ e corrente de $20 \mathrm{~mA}$, intervalo de varredura entre $10^{\circ}$ e $90^{\circ}(2 \theta)$ e velocidade do goniômetro de $2 \% \mathrm{~min}$.

Depois de obtidos os difratogramas, foram identificadas as fases minerais nos respectivos difratogramas com base nos padrões difratométricos da Inorganic Crystal Structure Database (ICSD).

\section{RESULTADOS E DISCUSSÃO: FLUORESCÊNCIA DE RAIOS X TIJOLOS DE IGARASSU E DO FORTE DO BRUM}

Os resultados das análises de fluorescência de raios $\mathrm{X}$ em quatro pontos da parte interna dos tijolos de Igarassu e Forte do Brum estão apresentados na Figura 2. Com base na curva de calibração foi possível identificar as energias correspondentes aos fotopicos.

A partir dos espectros e dos dados tabelados das energias dos raios $\mathrm{X}$ característicos da linha K(EG\&G ORTEC, 1980) foi possível identificar os elementos presentes nas amostras analisadas, que estão identificados nos espectros de fluorescência de raios X. Nos espectros também aparecem os fotopicos 
correspondentes as linhas $\mathrm{L}$ do tungstênio $(\mathrm{W})$, as quais correspondem à radiação proveniente do anodo do tubo de raios $\mathrm{X}$.

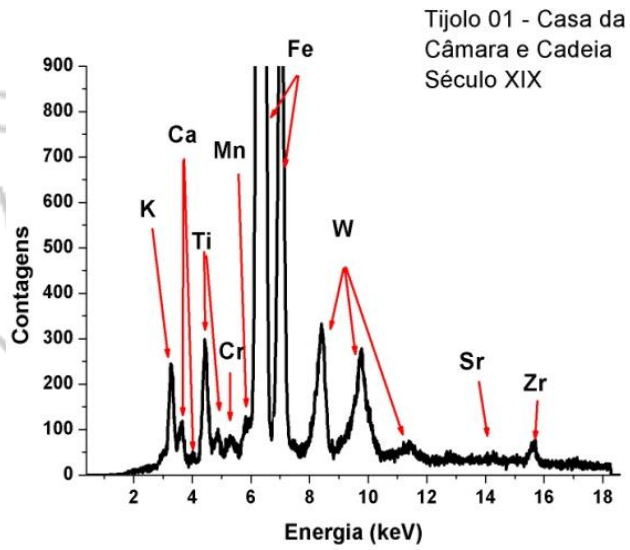

(a)

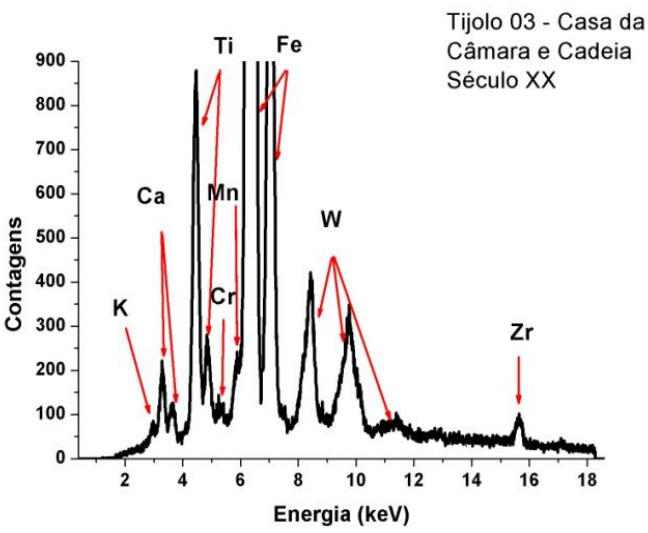

(c)

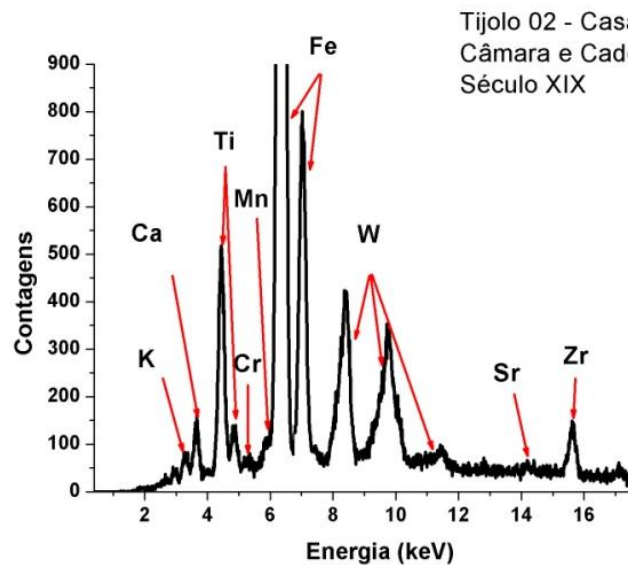

(b)

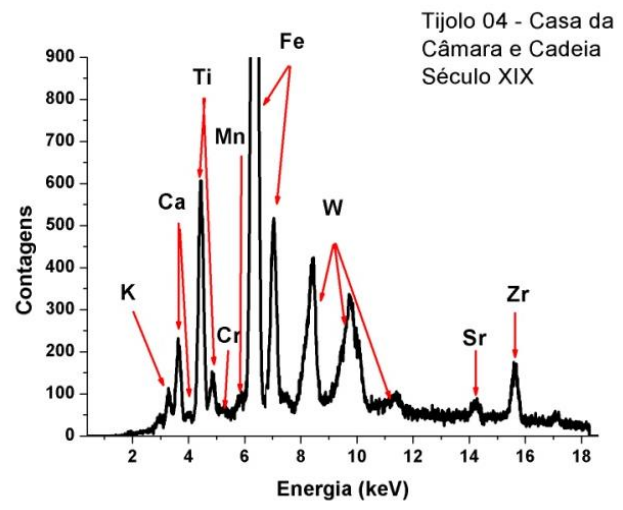

(d) 


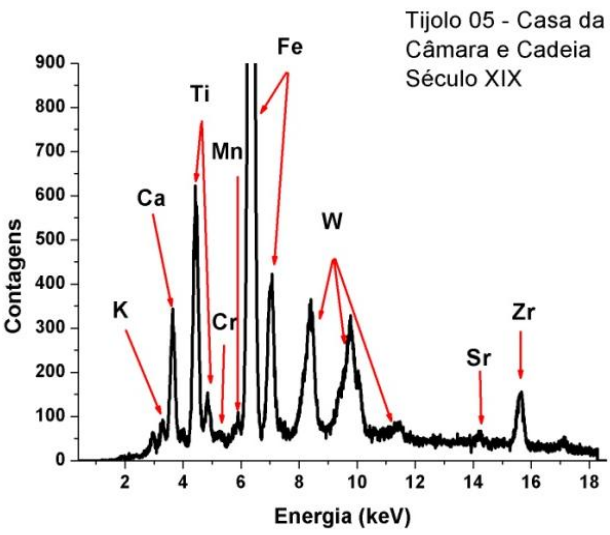

(e)

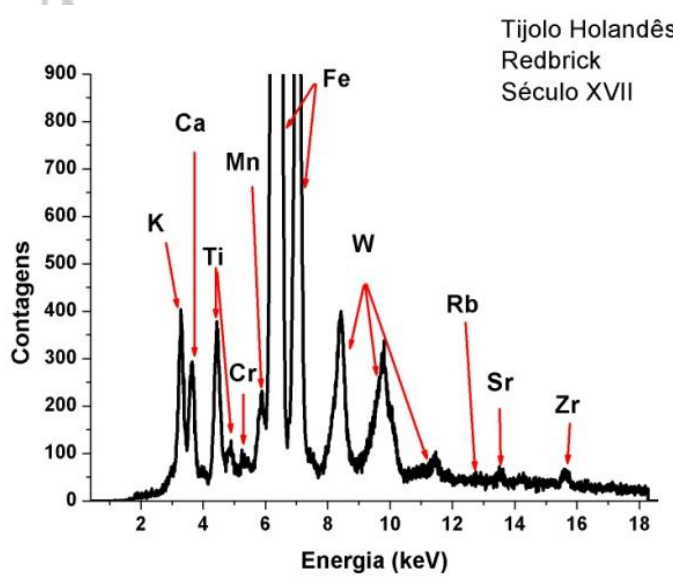

(g)

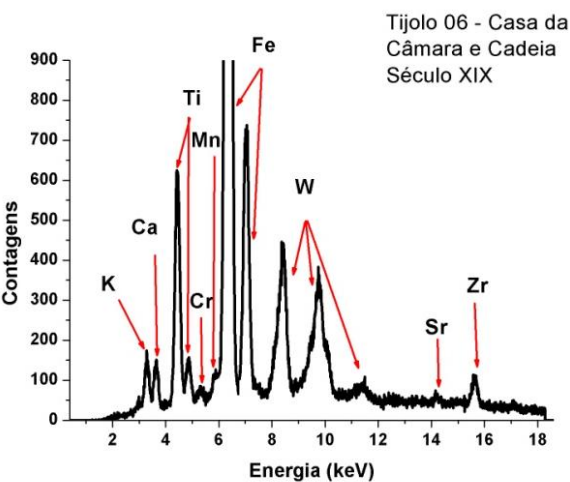

(f)

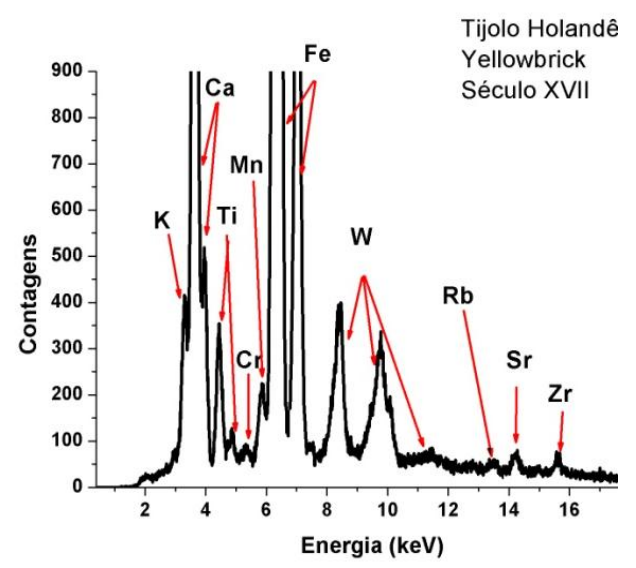

(h) 


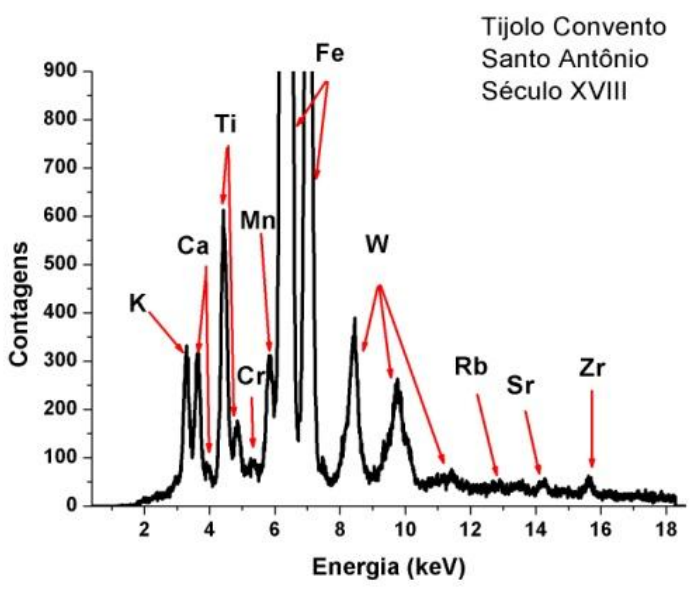

(i)

Figura 2: Espectros de fluorescência de raios $\mathrm{X}$ obtidos em um ponto de medida nos tijolos de Igarassu.

Os espectros foram analisados utilizando-se o programa AXIL e, então, foram determinadas as áreas de cada fotopico através do software AXIL. Nas Tabelas 1 e 2 são apresentados os valores médios das áreas dos picos, resultantes de quatro medidas de fluorescência de raios $\mathrm{X}$ nos tijolos e seus respectivos coeficientes de variação. O coeficiente de variação foi calculado utilizando a seguinte equação:

$$
\text { coef } \text {, de variação }(\%)=\frac{\text { desvio padrão }}{\bar{x}} \times 100(1)
$$

A Figura mostra o histograma correspondente dos dados apresentados nas tabelas. Observa-se que em todos os tijolos foram encontrados os seguintes elementos: potássio $(\mathrm{K})$, cálcio $(\mathrm{Ca})$, titânio $(\mathrm{Ti})$, Cromo $(\mathrm{Cr})$, manganês $(\mathrm{Mn})$, 
ferro $(\mathrm{Fe})$, estrôncio $(\mathrm{Sr})$ e zircônio $(\mathrm{Zr})$. O elemento químico rubídio $(\mathrm{Rb})$ foi detectado apenas nos tijolos Redbrick, Yellowbrick e o do Convento Santo Antonio, enquanto que o Ítrio (Y) apareceu apenas no tijolo da Casa da Câmara e Cadeia de Igarassu $n^{\circ} 03$.

Observa-se também que em todos os tijolos o teor de ferro é elevado, sendo que os menores valores das áreas dos fotopicos das linhas $\mathrm{K}$ do ferro foram encontrados nos tijolos da Casa da Câmara e Cadeia do século XIX. Analisandose o tijolo Yellowbrick, nota-se que o teor de cálcio é superior quando comparado aos outros tijolos. Trabalhos de SOPKO \& MCEVOY (1991) ao analisarem tijolos holandeses provenientes de quatro sítios históricos de Nova York mostraram também a presença de ferro, rubídio, estrôncio, zircônio e ítrio.

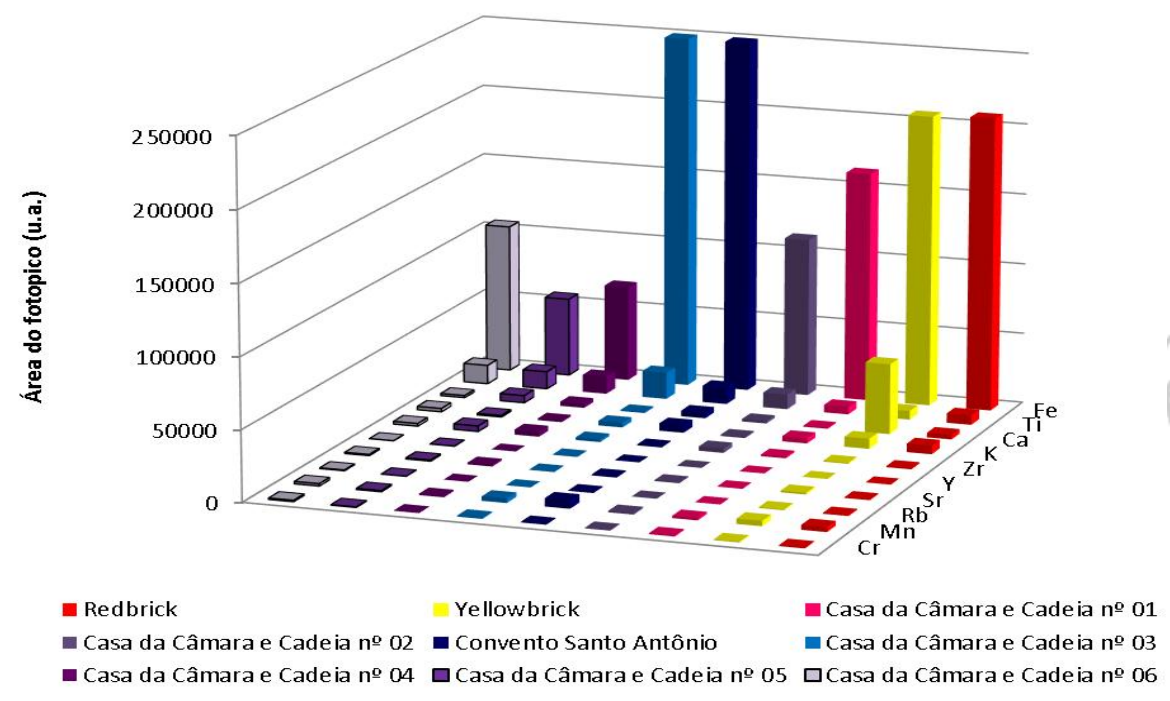

Figura 4: Histograma representativo das áreas dos elementos constituintes dos tijolos. 
A partir dos dados dos espectros e utilizando o programa "The Unscramble" v9.2. da CAMO PROCESS, foi realizada a análise de componentes principais (ACP). A ACP é um método estatístico de análise multivariada, que procura identificar os comportamentos semelhantes e distintos entre amostras. A informação relativa ao conjunto de dados originais é sintetizada nos gráficos de scores e loadings. Através do gráfico de loadings é possível identificar as variáveis que são responsáveis pelos agrupamentos, enquanto o gráfico do scores fornece informações sobre as amostras (MARENGO et al., 2005).

\begin{tabular}{|c|c|c|c|c|c|c|c|c|c|c|c|}
\hline Elemento & Energia & Tijolo & $\begin{array}{l}\text { Coef. de } \\
\text { variação }\end{array}$ & Tijolo & $\begin{array}{l}\text { Coef. de } \\
\text { variação }\end{array}$ & $\begin{array}{c}\text { Tijolo do } \\
\text { Conv. } \\
\text { Santo } \\
\text { Antônio }\end{array}$ & $\begin{array}{c}\text { Coef. de } \\
\text { variação }\end{array}$ & $\begin{array}{c}\text { Tijolo da } \\
\text { Casa da } \\
\text { Câmara e } \\
\text { Cadeia }\end{array}$ & $\begin{array}{c}\text { Coef. de } \\
\text { variação }\end{array}$ & $\begin{array}{c}\text { Tijolo da } \\
\text { Casa da } \\
\text { Câmara e } \\
\text { Cadeia }\end{array}$ & $\begin{array}{l}\text { Coef: de } \\
\text { variação }\end{array}$ \\
\hline químico & Ka (keV) & Redbrick & $(\%)$ & Yellowbrick & $(\%)$ & & $(\%)$ & $\mathrm{n}^{0} 01$ & $(\%)$ & $\mathrm{n}^{0} 02$ & $(\%)$ \\
\hline K & 3,312 & 6023 & 1,8 & 7103 & 1,7 & 5274 & 2,1 & 3749 & 2,2 & 924 & 5,9 \\
\hline $\mathrm{Ca}$ & 3,69 & 3228 & 3,4 & 49800 & 0,98 & 4054 & 3,3 & 732 & 8,9 & 1811 & 4,3 \\
\hline $\mathrm{Ti}$ & 4,538 & 6774 & 1,5 & 6184 & 1,7 & 11837 & 1,1 & 5358 & 1,6 & 10592 & 1,1 \\
\hline $\mathrm{Cr}$ & 5,411 & 617 & 10 & 587 & 11 & 425 & 15 & 759 & 7,1 & 321 & 17 \\
\hline $\mathrm{Mn}$ & 5,894 & 3333 & 2,5 & 3654 & 2,4 & 5784 & 1,8 & 1552 & 4,2 & 1035 & 6,1 \\
\hline $\mathrm{Fe}$ & 5,894 & 208595 & 0,22 & 206814 & 0,22 & 262864 & 0,2 & 162828 & 0,25 & 112325 & 0,31 \\
\hline $\mathrm{Rb}$ & 13,373 & 632 & 8,6 & 594 & 8,8 & 489 & 10 & NI* & NI* & $\mathrm{NI}^{*}$ & NI* \\
\hline $\mathrm{Sr}$ & 14,14 & 507 & 10 & 1186 & 4,9 & 749 & 6,7 & 243 & 19 & 571 & 9,4 \\
\hline $\mathrm{Y}$ & 14,931 & $\mathrm{NI}^{*}$ & $\mathrm{NI} *$ & $\mathrm{NI} *$ & $\mathrm{NI} *$ & $\mathrm{NI}^{*}$ & $\mathrm{NI} *$ & $\mathrm{NI}^{*}$ & $\mathrm{NI}^{*}$ & NI* & NI* \\
\hline $\mathrm{Zr}$ & 15,744 & 778 & 7,3 & 741 & 7,6 & 706 & 7,2 & 1229 & 4,7 & 3157 & 2,5 \\
\hline
\end{tabular}

* NI - Não Identificado.

Tabela 1: Valores médios das áreas dos picos dos elementos químicos constituintes nos tijolos, obtidos com 30 min de medida. 


\begin{tabular}{|c|c|c|c|c|c|c|c|c|c|}
\hline $\begin{array}{l}\text { Elemento } \\
\text { químico }\end{array}$ & $\begin{array}{c}\text { Energia } \\
\mathrm{K} \alpha(\mathrm{keV})\end{array}$ & $\begin{array}{c}\text { Tijolo da } \\
\text { Casa da } \\
\text { Câmara e } \\
\text { Cadeia no } \\
03\end{array}$ & $\begin{array}{c}\text { Coef. de } \\
\text { variação } \\
(\%)\end{array}$ & $\begin{array}{c}\text { Tijolo da } \\
\text { Casa da } \\
\text { Câmara e } \\
\text { Cadeia no } \\
04\end{array}$ & $\begin{array}{c}\text { Coef. de } \\
\text { variação } \\
(\%)\end{array}$ & $\begin{array}{c}\text { Tijolo da } \\
\text { Casa da } \\
\text { Câmara e } \\
\text { Cadeia no } \\
05\end{array}$ & $\begin{array}{c}\text { Coef. de } \\
\text { variação } \\
(\%)\end{array}$ & $\begin{array}{c}\text { Tijolo da } \\
\text { Casa da } \\
\text { Câmara e } \\
\text { Cadeia no } \\
06\end{array}$ & $\begin{array}{c}\text { Coef. de } \\
\text { variação } \\
(\%)\end{array}$ \\
\hline $\mathbf{K}$ & 3,312 & 3239 & 2,4 & 1215 & 4,9 & 1032 & 4,8 & 1034 & 2,6 \\
\hline $\mathrm{Ca}$ & 3,69 & 782 & 10 & 3019 & 3,3 & 5141 & 2,1 & 5143 & 4,9 \\
\hline $\mathbf{T i}$ & 4,538 & 18846 & 0,81 & 12371 & 1 & 12379 & 0,99 & 12380 & 0,95 \\
\hline $\mathrm{Cr}$ & 5,411 & 747 & 9,1 & 353 & 15 & 243 & 20,1 & 244 & 7 \\
\hline Mn & 5,894 & 3086 & 2,8 & 971 & 6,2 & 686 & 8 & 686 & 4,4 \\
\hline $\mathrm{Fe}$ & 5,894 & 265255 & 0,22 & 67746 & 0,4 & 55552 & 0,44 & 55551 & 0,32 \\
\hline $\mathbf{R b}$ & 13,373 & NI* & NI* & NI* & $\mathrm{NI}^{*}$ & NI* & $\mathrm{NI*}$ & $N I^{*}$ & NI* \\
\hline $\mathrm{Sr}$ & 14,14 & 345 & 13 & 1289 & 5,1 & 707 & 7,2 & 707 & 6,81 \\
\hline $\mathbf{Y}$ & 14,931 & 325 & 14 & NI* & $\mathrm{NI}^{*}$ & NI* & NI* & $\mathrm{NI} *$ & $\mathrm{NI}^{*}$ \\
\hline $\mathbf{Z r}$ & 15,744 & 1927 & 3,3 & 3710 & 2,4 & 3903 & 2 & 3902 & 3,5 \\
\hline
\end{tabular}

* NI - Não Identificado.

Tabela 2: Valores médios das áreas dos picos dos elementos químicos constituintes nos tijolos, obtidos com 30 min de medida.

Com intuito de avaliar as possíveis semelhanças e diferenças entre as amostras foi aplicada a análise por componentes principais nos espectros obtidos por fluorescência de raios X. Inicialmente, foi realizado um pré-processamento nos dados, normalizando-os e aplicando uma correção de linha de base. A normalização tem a finalidade de aproximar todos os dados à mesma escala, enquanto que a transformação baseline é utilizada para corrigir o efeito de linha de base dos espectros das amostras. Então a análise de componentes principais foi aplicada utilizando as contagens obtidas para todo o espectro, ou seja, utilizando 
2048 canais como variáveis. Os resultados obtidos para os tijolos do Forte do Brum, Convento Santo Antônio e Casa de Câmara e Cadeia estão apresentados na Erro! Fonte de referência não encontrada. 5. As coordenadas CP1 e CP3 representam a influência positiva das variáveis ferro $(\mathrm{Fe})$ e cálcio $(\mathrm{Ca})$, respectivamente.

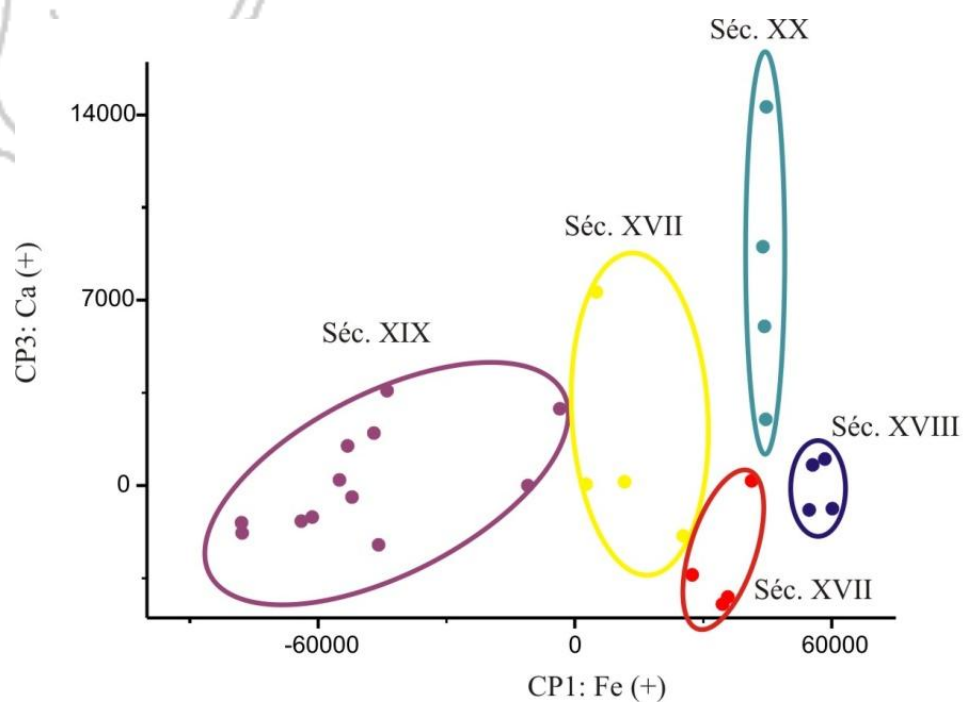

- Tijolo Holandês Red brick Século XVII

Tijolo Holandês Yellow brick Século XVII

- Tijolo do Convento Santo Antônio Século XVIII

- Tijolos da Casa da Cârama e Cadeia Século XIX

- Tijolo n03 da Casa da Câmara e Cadeia Século XX

Figura 5: Scores dos espectros de XRF dos tijolos de Igarassu e Forte do Brum obtidos por ACP.

Os resultados mostram o agrupamento dos tijolos de acordo com o século de origem. Observa-se que os tijolos holandeses, junto com os do Convento Santo Antônio e da Casa da Câmara e Cadeia no 03 (século XX) encontram-se no eixo positivo de CP1, indicando uma presença mais elevada de ferro, o que já foi constatado anteriormente na Figura 3. O tijolo da Casa da Câmara e Cadeia de 
Igarassu $\mathrm{n}^{\mathrm{o}} 3$ (século XX) encontra-se mais deslocado no eixo superior, em relação a CP2, indicando que possui maior teor de cálcio em relação aos demais. Mesmo conseguindo separar os tijolos por século, a grande quantidade de ferro presente em todas as amostras predomina na avaliação dos dados.

\section{Tijolos de Olinda}

Os espectros de cada tipo de tijolo são apresentados na Figura 6, onde estão indicadas as linhas $\mathrm{K}$ dos elementos químicos constituintes e as linhas $\mathrm{L}$ do tungstênio (W) proveniente do anodo do tubo de raios $\mathrm{X}$.

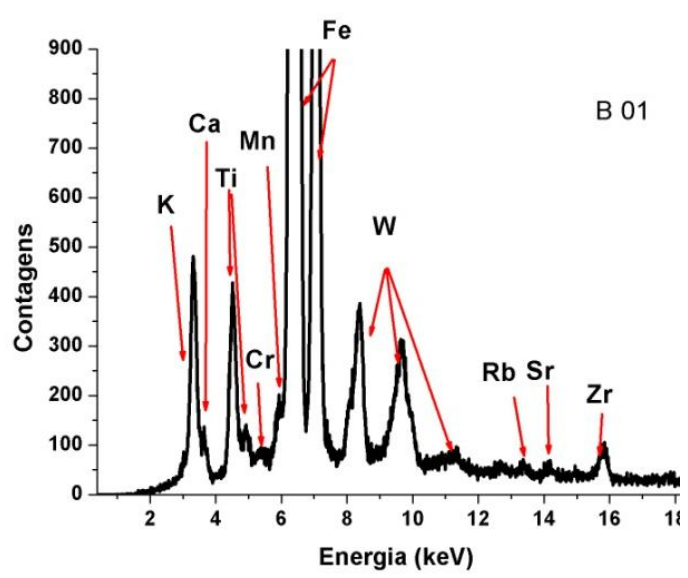

(a)

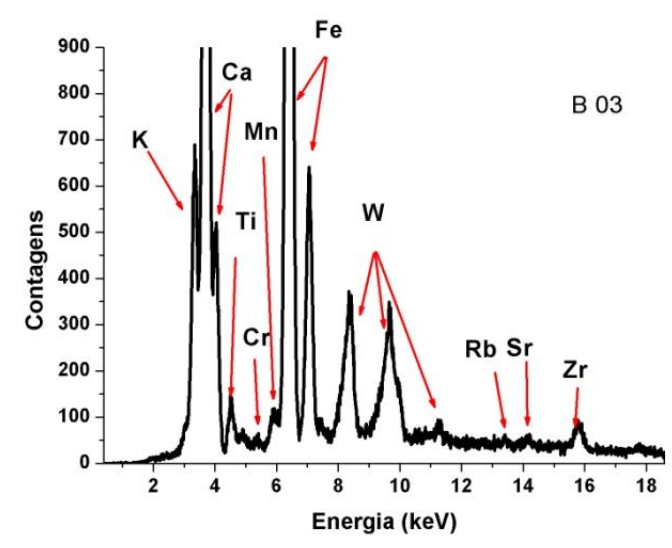

(b) 


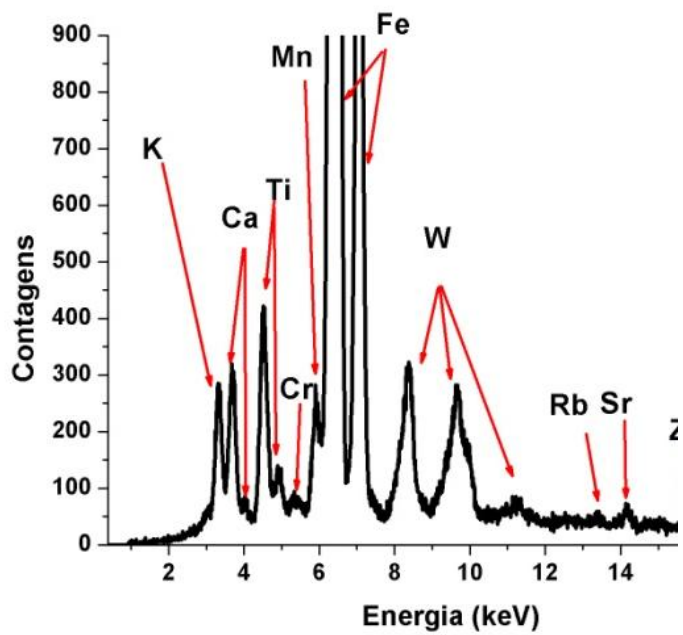

(c)

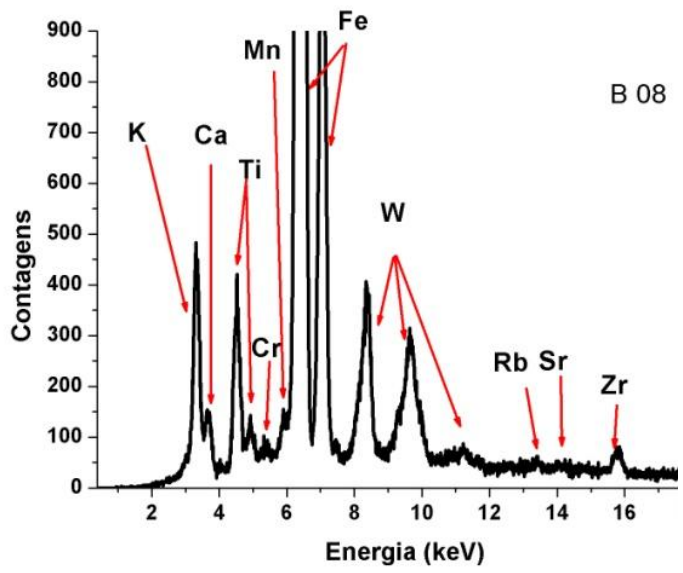

(e)

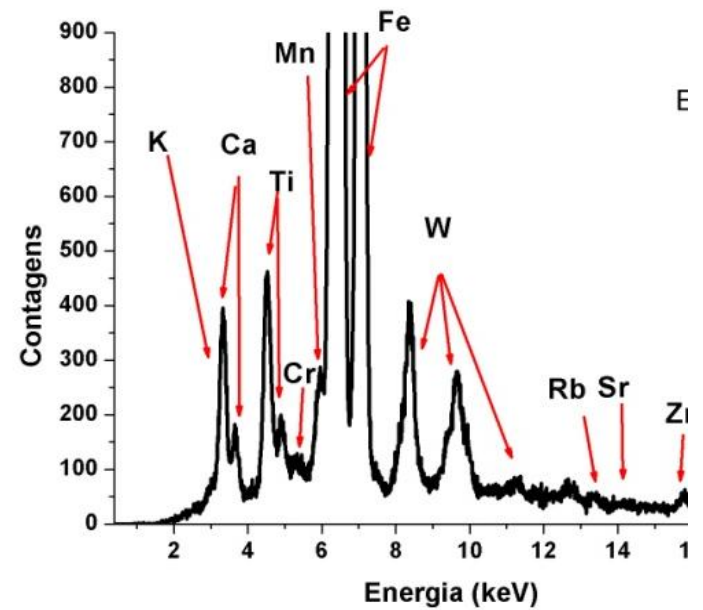

(d)

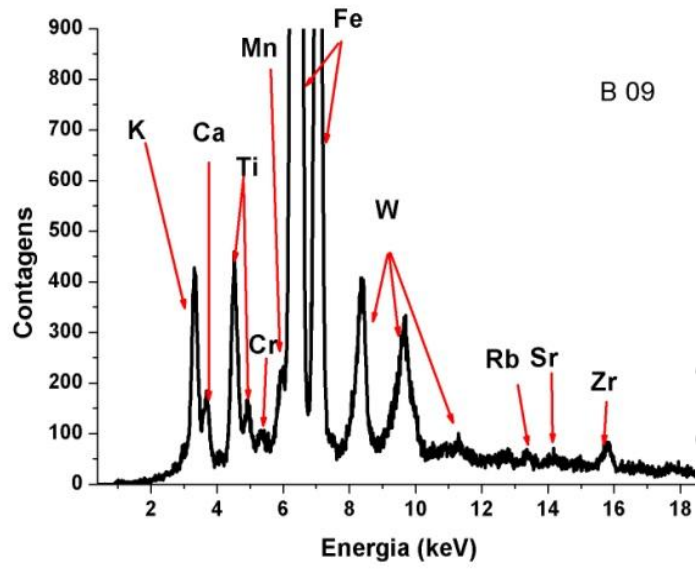

(f) 


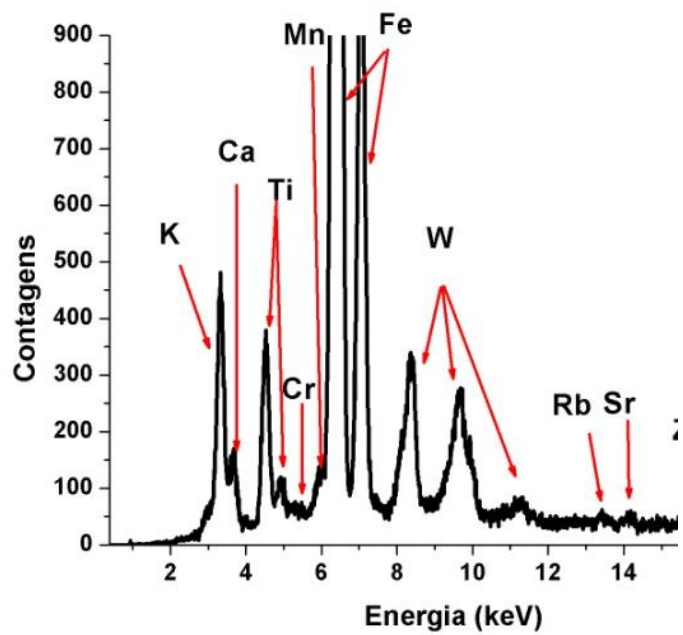

(g)

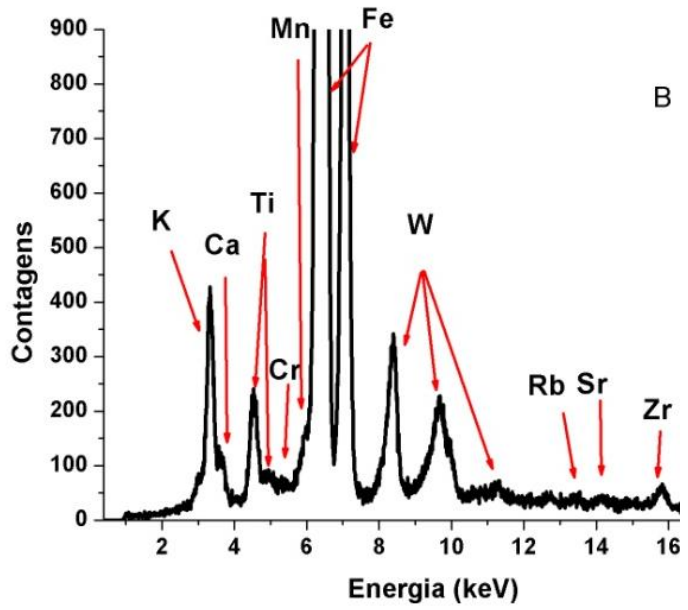

(i)

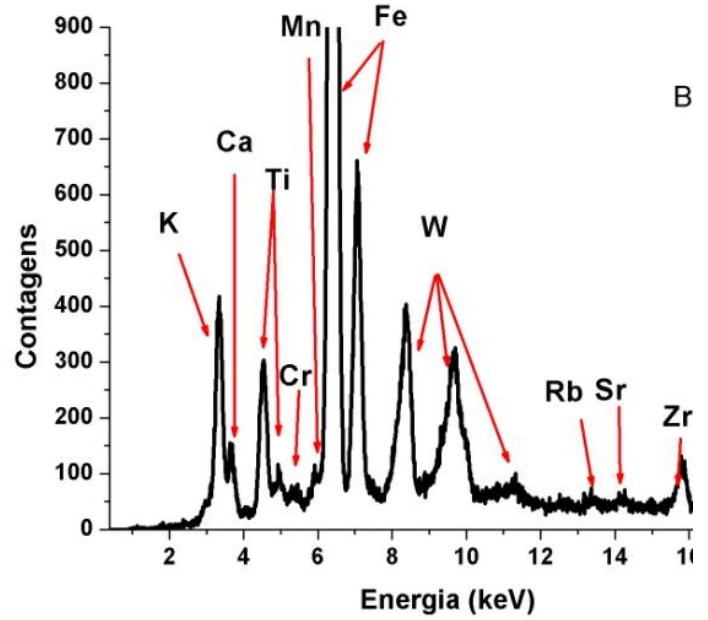

(h)

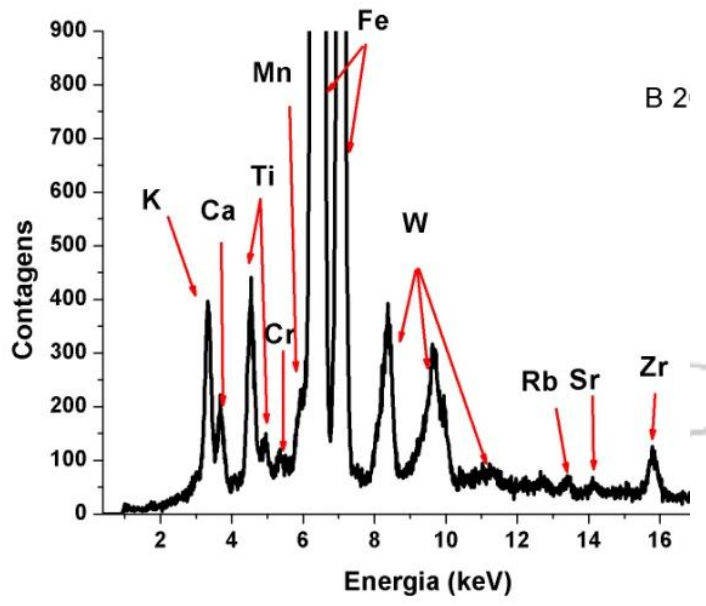

(j) 


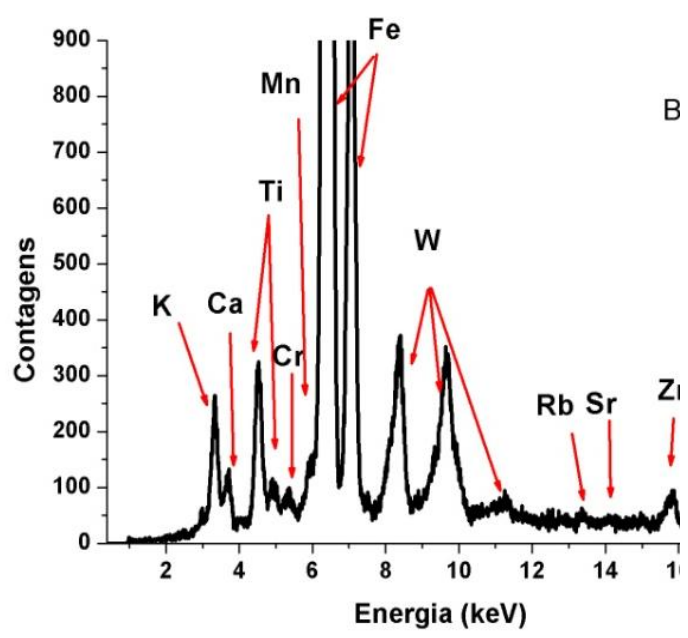

(I)

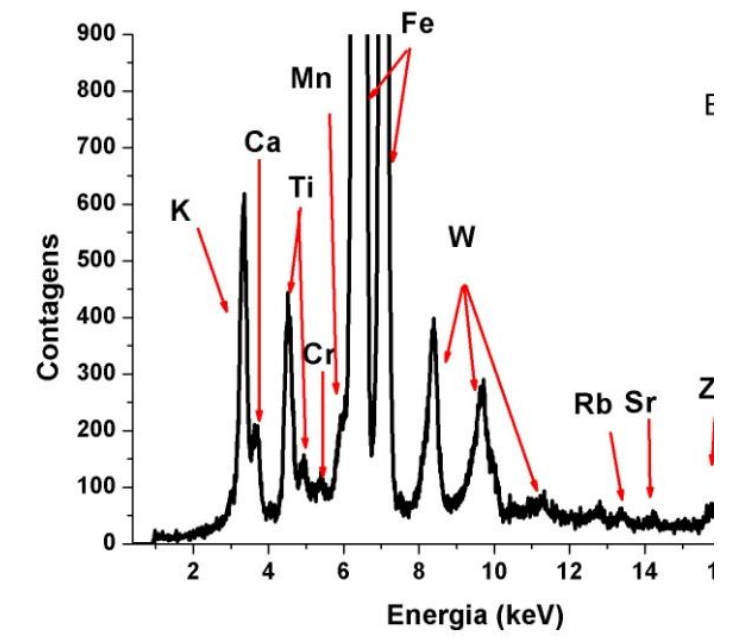

(m)

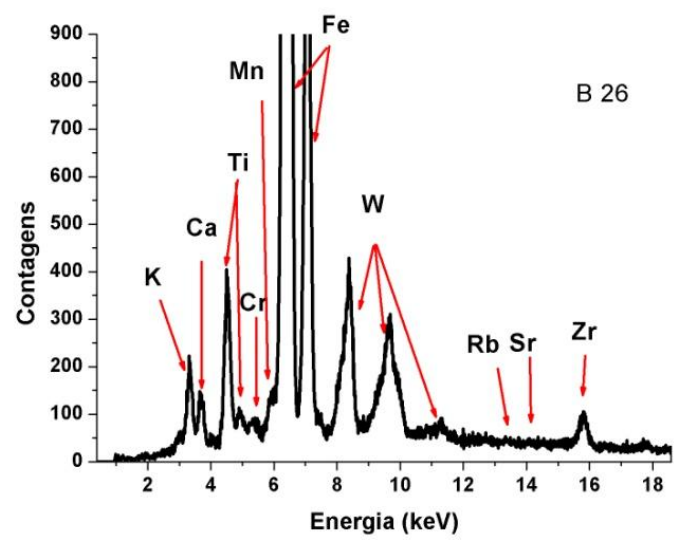

(n)

Figura 6: Espectros de fluorescência de raios $\mathrm{X}$ das amostras de tijolos de Olinda: (a) B01; (b) B03; (c) B05; (d) B07; (e) B08; (f) B09; (g) B10; (h) B13; (i) B16; (j) B20; (l) B23; (m) B24; (n) B26; 
Nas Tabelas 3, 4 e 5 são apresentados os valores médios das áreas dos picos dos elementos químicos constituintes dos tijolos obtidos nas medidas de fluorescência de raios $X$ durante 30 minutos. A Figura 7 mostra o histograma correspondente dos resultados obtidos por XRF.

Observa-se que os elementos encontrados são praticamente os mesmos detectados nos tijolos de Igarassu e Forte do Brum. A diferença encontra-se na completa ausência de ítrio e na presença de rubídio em todos os tijolos.

Nota-se que os tijolos B07 e B09 apresentam um teor de ferro bem mais elevado em relação aos demais, inclusive mais do que os tijolos do grupo Igarassu e Forte do Brum. Observa-se também que diferentemente do grupo anterior, a maioria destes tijolos apresentam uma quantidade de cálcio inferior à de potássio.

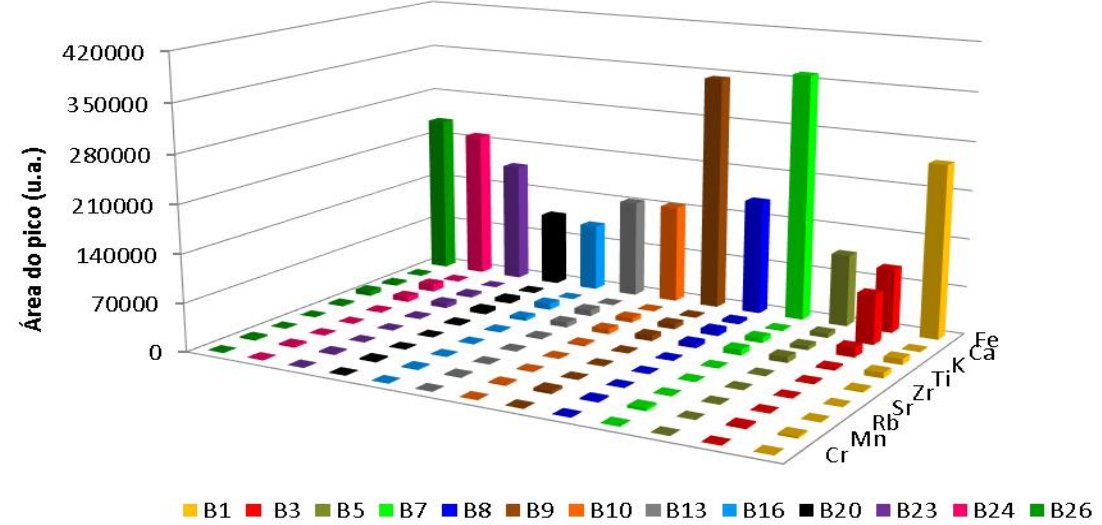

Figura 7: Histograma representativo das áreas dos elementos constituintes dos tijolos. 


\begin{tabular}{|c|c|c|c|c|c|c|c|c|c|c|c|}
\hline $\begin{array}{c}\text { Elemento } \\
\text { químico }\end{array}$ & $\begin{array}{c}\text { Energia } \\
(\mathrm{keV})\end{array}$ & B1 & $\begin{array}{c}\text { Coef. de } \\
\text { variação } \\
(\%)\end{array}$ & B3 & $\begin{array}{c}\text { Coef. de } \\
\text { variação } \\
(\%)\end{array}$ & B5 & $\begin{array}{c}\text { Coef. de } \\
\text { variação } \\
(\%)\end{array}$ & B7 & $\begin{array}{c}\text { Coef. de } \\
\text { variação } \\
(\%)\end{array}$ & B8 & $\begin{array}{c}\text { Coef. de } \\
\text { variação } \\
(\%)\end{array}$ \\
\hline K & 3,313 & 8338 & 1,3 & 14098 & 0,10 & 5734 & 1,6 & 7433 & 1,4 & 8047 & 1,3 \\
\hline $\mathrm{Ca}$ & 3,691 & 971 & 8,2 & 73035 & 0,04 & 6483 & 1,9 & 1700 & 5,3 & 4399 & 2,4 \\
\hline $\mathrm{Ti}$ & 4,509 & 7660 & 1,4 & 2860 & 0,37 & 8443 & 1,3 & 8298 & 1,4 & 6817 & 1,4 \\
\hline $\mathrm{Cr}$ & 5,412 & 408 & 15 & NI* & NI* & 550 & 10 & 674 & 9,3 & 481 & 11 \\
\hline $\mathrm{Mn}$ & 5,895 & 2556 & 3,1 & 2612 & 0,40 & 4894 & 1,8 & 3766 & 2,3 & 1926 & 3,6 \\
\hline $\mathrm{Fe}$ & 6,399 & 252950 & 0,20 & 93322 & 0,02 & $\begin{array}{c}10532 \\
8\end{array}$ & 0,47 & 360997 & 0,17 & $\begin{array}{c}16818 \\
3\end{array}$ & 0,25 \\
\hline $\mathrm{Rb}$ & 13,375 & 394 & 13 & 502 & 1,7 & 485 & 10 & 542 & 9,2 & 645 & 7,4 \\
\hline $\mathrm{Sr}$ & 14,142 & 424 & 11 & 698 & 1,2 & 1006 & 5,2 & 517 & 8,7 & 656 & 6,9 \\
\hline $\mathrm{Zr}$ & 15,746 & 1687 & 3,6 & 1335 & 0,68 & 873 & 5,8 & 1204 & 4,5 & 1417 & 3,8 \\
\hline
\end{tabular}

*NI - Não Identificado.

Tabela 3: Valores médios das áreas dos picos $\mathrm{K}$ dos elementos detectados nas medidas durante um tempo de 30 minutos nos tijolos B1, B3, B5, B7 e B8.

\begin{tabular}{|c|c|c|c|c|c|c|c|c|c|c|c|}
\hline $\begin{array}{c}\text { Elemento } \\
\text { químico }\end{array}$ & $\begin{array}{c}\text { Energia } \\
(\mathrm{keV})\end{array}$ & B9 & $\begin{array}{c}\text { Coef. de } \\
\text { variação } \\
(\%)\end{array}$ & B10 & $\begin{array}{c}\text { Coef. de } \\
\text { variação } \\
(\%)\end{array}$ & B13 & $\begin{array}{c}\text { Coef. de } \\
\text { variação } \\
(\%)\end{array}$ & B16 & $\begin{array}{c}\text { Coef. de } \\
\text { variação } \\
(\%)\end{array}$ & B20 & $\begin{array}{c}\text { Coef. de } \\
\text { variação } \\
(\%)\end{array}$ \\
\hline K & 3,313 & 7356 & 1,4 & 6678 & 1,3 & 8643 & 1,2 & 9036 & 1,2 & 6011 & 1,5 \\
\hline $\mathrm{Ca}$ & 3,691 & 1658 & 5,4 & 1119 & 6,4 & 736 & 10 & NI* & NI* & 1758 & 4,8 \\
\hline $\mathrm{Ti}$ & 4,509 & 7515 & 1,4 & 6988 & 1,4 & 7200 & 1,4 & 4524 & 1,8 & 6208 & 1,6 \\
\hline $\mathrm{Cr}$ & 5,412 & 678 & 9,1 & 487 & 10 & 506 & 12 & 437 & 12 & 602 & 9,7 \\
\hline $\mathrm{Mn}$ & 5,895 & 4349 & 2,0 & 1467 & 4,3 & 1552 & 4,4 & 1574 & 4,0 & 2367 & 3,1 \\
\hline $\mathrm{Fe}$ & 6,399 & $\begin{array}{c}3440 \\
03 \\
\end{array}$ & 0,17 & $\begin{array}{c}1445 \\
06 \\
\end{array}$ & 0,26 & $\begin{array}{c}1434 \\
63 \\
\end{array}$ & 0,27 & 99240 & 0,36 & 107037 & 0,42 \\
\hline $\mathrm{Rb}$ & 13,375 & 496 & 10 & 654 & 7,5 & 636 & 8,0 & 607 & 7,8 & 564 & 9,0 \\
\hline $\mathrm{Sr}$ & 14,142 & 553 & 8,3 & 759 & 6,3 & 729 & 6,8 & 739 & 6,4 & 692 & 7,2 \\
\hline $\mathrm{Zr}$ & 15,746 & 1178 & 4,6 & 2306 & 2,8 & 2013 & 3,1 & 1500 & 3,8 & 2160 & 3,0 \\
\hline
\end{tabular}

*NI - Não Identificado.

Tabela 4: Valores médios das áreas dos picos $\mathrm{K}$ dos elementos detectados nas medidas durante um tempo de 30 minutos nos tijolos B9, B10, B13, B16 e B20. 


\begin{tabular}{|c|c|c|c|c|c|c|c|}
\hline $\begin{array}{c}\text { Elemento } \\
\text { químico }\end{array}$ & $\begin{array}{c}\text { Energia } \\
\mathbf{( k e V )}\end{array}$ & $\mathbf{B 2 3}$ & $\begin{array}{c}\text { Coef. de } \\
\text { variação } \\
(\mathbf{\%})\end{array}$ & $\mathbf{B 2 4}$ & $\begin{array}{c}\text { Coef. de } \\
\text { variação } \\
(\mathbf{\%})\end{array}$ & B26 & $\begin{array}{c}\text { Coef. de } \\
\text { variação } \\
\text { (\%) }\end{array}$ \\
\hline $\mathrm{K}$ & 3,313 & 3731 & 1,1 & 11153 & 1 & 3042 & 2,3 \\
\hline $\mathrm{Ca}$ & 3,691 & 522 & 6,2 & 1455 & 6,3 & 1540 & 5 \\
\hline $\mathrm{Ti}$ & 4,509 & 7162 & 1,4 & 7674 & 1,3 & 7229 & 1,4 \\
\hline $\mathrm{Cr}$ & 5,412 & 598 & 8,8 & 686 & 8,7 & 504 & 11 \\
\hline $\mathrm{Mn}$ & 5,895 & 1961 & 2,9 & 2634 & 2,9 & 2364 & 3,1 \\
\hline $\mathrm{Fe}$ & 6,399 & 177687 & 0,21 & 219545 & 0,21 & 237359 & 0,21 \\
\hline $\mathrm{Rb}$ & 13,375 & 441 & 9,4 & 528 & 8,3 & 376 & 13 \\
\hline $\mathrm{Sr}$ & 14,142 & 504 & 9,1 & 514 & 9,1 & 391 & 11 \\
\hline $\mathrm{Zr}$ & 15,746 & 1841 & 3,9 & 1441 & 3,3 & 2229 & 2,9 \\
\hline
\end{tabular}

*NI - Não Identificado.

Tabela 5: Valores médios das áreas dos picos $\mathrm{K}_{\square}$ dos elementos detectados nas medidas durante um tempo de 30 minutos nos tijolos B23, B24.

Para a realização da análise de componentes principais, foi utilizado o mesmo préprocessamento nos dados dos espectros dos tijolos de Olinda, ou seja, primeiro uma normalização seguida da correção de linha de base. A Figura8 apresenta os resultados obtidos por ACP. Os elementos que mais influenciaram na variância observada são considerados como as variáveis mais importantes do ponto de vista estatístico e são os que apresentam maiores pesos nas duas primeiras componentes principais. Assim, a coordenada CP1 é formada pela influência positiva do ferro e negativa do cálcio, enquanto que a CP2 representa uma influência positiva do ferro e cálcio. 


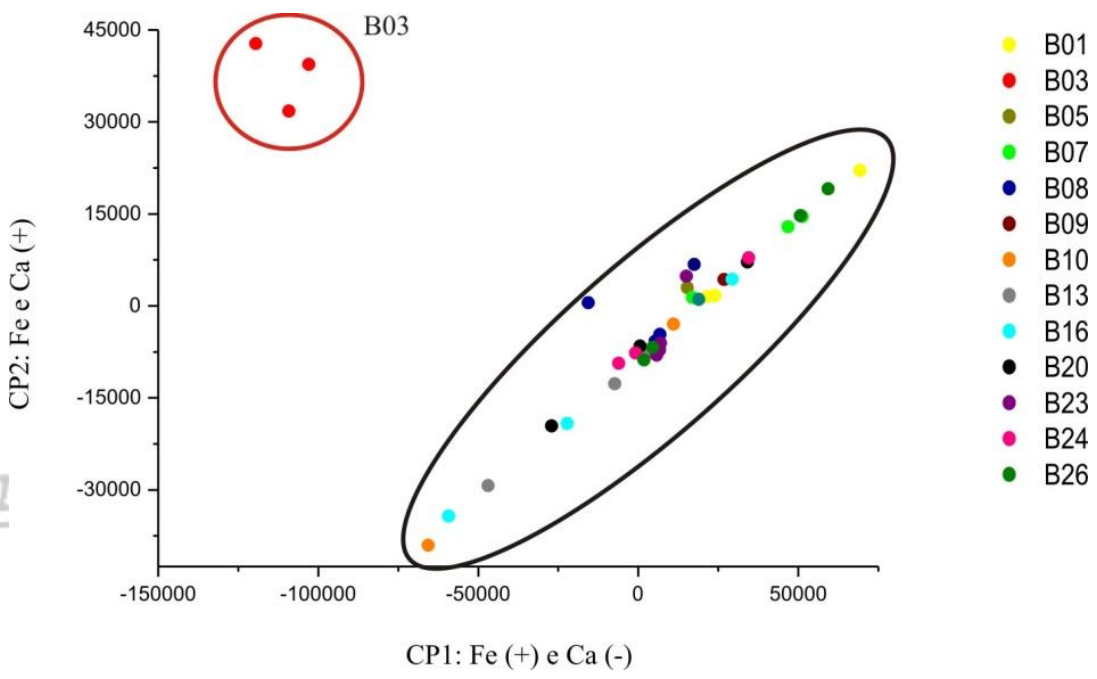

Figura 8: Scores dos espectros de XRF dos tijolos de Olinda obtidos por ACP.

Observa-se que foi possível separar o tijolo B03 dos demais. Assim, estando isto relacionado ao maior conteúdo de cálcio presente neste tijolo comparativamente aos demais, conclui-se que apesar dos valores das áreas dos fotopicos dos elementos constituintes das amostras variarem, isso não acarreta uma diferença significativa entre eles, ou seja, pode-se afirmar que todos os tijolos deste grupo possuem constituições semelhantes.

Com intuito de comparar as análises de fluorescência de raios $\mathrm{X}$ dos tijolos de Olinda com os de Igarassu e Forte de Brum, foi realizada uma ACP entre esses dois grupos. A componente principal 1 (CP1) é composta basicamente pela influência positiva do ferro. E a componente principal 2 (CP2), pela influência 
positivamente do cálcio. A Figura9 apresenta os scores obtidos na ACP de todos os tijolos analisados.

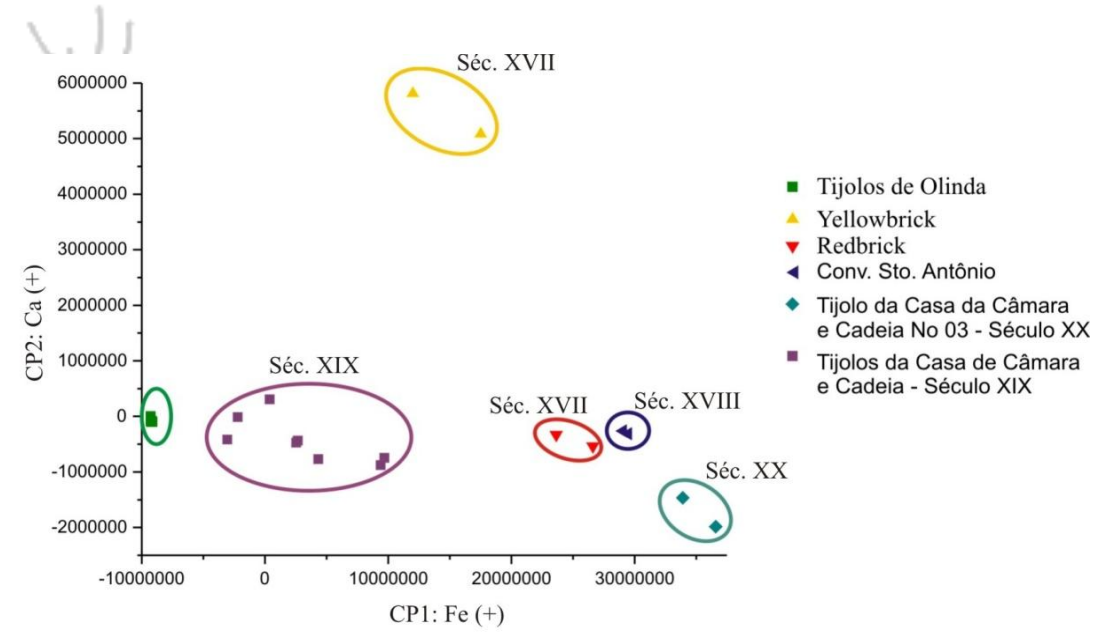

Figura 9: Scores dos espectros de XRF dos tijolos de Olinda, Igarassu e Forte do Brum obtidos por ACP.

Novamente houve a separação entre os tijolos do primeiro grupo de acordo com o século. Nesta análise observa-se também que todos os tijolos de Olinda ficaram agrupados, distinguindo-se dos demais e aproximando-se dos tijolos do século XIX.

\section{Difração de raios $X$}

As análises de difração de raios $\mathrm{X}$ identificaram fases minerais com boa cristalinidade, mesmo após a queima que é parte do processo de manufatura dos tijolos, sendo o quartzo o principal mineral detectado. Outras fases minerais foram 
identificadas baseadas na presença dos picos principais, ainda que menos expressivos nos difratogramas, refletindo a preservação das estruturas cristalinas dos minerais de origem mesmo após a queima. Não foram identificadas fases minerais ricas em ferro, magnésio, cálcio, provavelmente por já se apresentarem como constituintes amorfos.

Os difratogramas dos tijolos do século XIX da Casa da Câmara e Cadeia apresentaram-se semelhantes, constituindo-se essencialmente de quartzo $\left(\mathrm{SiO}_{2}\right)$. O único tijolo do século XX da Casa da Câmara e Cadeia apresentou, além do quartzo, a presença de ilita e uma provável existência de rutilo $\left(\mathrm{TiO}_{2}\right)$. A Tabela 6 apresenta um resumo das fases minerais identificadas por DRX após análise dos difratogramas.

\begin{tabular}{|c|c|c|c|c|}
\hline $\begin{array}{c}\text { Casa da } \\
\text { Câmara e } \\
\text { Cadeia } \\
\text { (Século XIX) }\end{array}$ & $\begin{array}{c}\text { Casa da } \\
\text { Câmara e } \\
\text { Cadeia } \mathbf{N}^{\circ} 03 \\
\text { (Século XX) }\end{array}$ & $\begin{array}{c}\text { RedBrick } \\
\text { (Século XVII) }\end{array}$ & $\begin{array}{c}\text { Yellowbrick } \\
\text { (Século XVII) }\end{array}$ & $\begin{array}{c}\text { Convento } \\
\text { Santo } \\
\text { Antônio } \\
\text { (Século } \\
\text { XVIII) } \\
\end{array}$ \\
\hline \multirow[t]{3}{*}{$\begin{array}{l}\text { Quartzo } \\
{\left[\mathrm{SiO}_{2}\right]}\end{array}$} & Quartzo $\left[\mathrm{SiO}_{2}\right]$ & $\begin{array}{c}\text { Quartzo } \\
{\left[\mathrm{SiO}_{2}\right]}\end{array}$ & $\begin{array}{c}\text { Quartzo } \\
{\left[\mathrm{SiO}_{2}\right]}\end{array}$ & $\begin{array}{l}\text { Quartzo } \\
{\left[\mathrm{SiO}_{2}\right]}\end{array}$ \\
\hline & Ilita $^{1}$ & $\begin{array}{c}\text { Caulinita } \\
{\left[\mathrm{Al}_{4}\left(\mathrm{Si}_{4} \mathrm{O}_{10}\right)(\mathrm{O}\right.} \\
\left.\mathrm{H})_{8}\right]\end{array}$ & $\begin{array}{c}\text { Caulinita } \\
{\left[\mathrm{Al}_{4}\left(\mathrm{Si}_{4} \mathrm{O}_{10}\right)(\mathrm{O}\right.} \\
\left.\mathrm{H})_{8}\right]\end{array}$ & Ilita $^{1}$ \\
\hline & $\begin{array}{c}\text { Rutilo } \\
\left(\mathrm{TiO}_{2}\right) \\
\text { (provável) }\end{array}$ & & {$\left[\begin{array}{c}\text { Anortita } \\
{\left[\mathrm{CaAl}_{2} \mathrm{Si}_{2} \mathrm{O}_{8}\right]}\end{array}\right.$} & $\begin{array}{c}\text { Anortita } \\
{\left[\mathrm{CaAl}_{2} \mathrm{Si}_{2} \mathrm{O}_{8}\right]}\end{array}$ \\
\hline
\end{tabular}

Tabela 6. Rresumo das fases minerais identificadas por DRX após análise dos difratogramas. 
Os resultados mostram a clara presença do quartzo como mineral principal em todos os tijolos. A fluorescência de raios $\mathrm{X}$ verificou que para esses tijolos a quantidade de ferro é mais baixo que os demais e, pela difração de raios $\mathrm{X}$ não foram identificados a presença de óxidos e / ou hidróxidos de ferro cristalizados, ou por se encontrarem amorfos ou pela pequena concentração, sendo mascarados pela presença dominante da fase mineral quartzo.

A elevada quantidade de ferro do tijolo do Convento Santo Antônio não é identificada através de alguma fase mineral, podendo estar relacionado à presença de ferro em alguma fração amorfa. Este tijolo apresenta um dos valores mais elevados de cálcio, o qual deve relacionar-se com a presença provável de anortita no difratograma.

A presença de caulinita, detectada nos tijolos holandeses, segundo TEIXEIRA et al. (2004), está relacionada aos materiais utilizados para proporcionar uma boa plasticidade na produção de tijolos, que é um parâmetro importante para definir a qualidade e propriedades do produto final, tais como resistência mecânica, absorção de água, trincas, mudanças durante a secagem e queima.

Os difratogramas dos tijolos de Olinda estão apresentados no Apêndice. A interpretação destes dados com a identificação das fases minerais permitiu agrupar os tijolos de Olinda com base na presença de alguns minerais em: grupo I, tijolos 
que apresentaram mulita; grupo II tijolos com caulinita (metacaulinita) e ausência de mulita e grupo III, tijolos sem mulita e metacaulinita.

\section{CONSIDERAÇÕES FINAIS}

As análises dos tijolos (holandeses) do Forte do Brum mostraram características diferentes dos demais tijolos analisados, e similares a outros tijolos holandeses analisados por SOPKO e MCEVOY (1991), corroborando a hipótese de que foram trazidos ao país em navios vindos da Holanda.

Dentre os tijolos de Igarassu, o tijolo do Convento Santo Antônio (século XVIII) apresentou, pela fluorescência de raios X, que em sua composição existe teores de ferro mais elevados do que os demais tijolos dos séculos XIX e XX.

As análises de fluorescência de raios X dos tijolos de Igarassu da Casa da Câmara e Cadeia possibilitam a separação destes tijolos em dois grupos, um correspondente ao século XIX e outro ao século XX. Este resultado corrobora com as intervenções realizadas neste edifício, permitindo identificar as áreas em que foram realizadas as reformas.

A análise de fluorescência de raios $\mathrm{X}$ dos tijolos de Olinda mostrou que, com exceção do B03, todos os tijolos apresentaram constituição semelhante, ou seja, são de fabricação similar e pertencem ao mesmo sítio. 


\section{REFERÊNCIAS BIBLIOGRÁFICAS}

ARAUJO, R. A. D O ofício da Construção na cidade colonial - organização, materiais e técnicas ( $O$ caso pernambucano) Tese de Doutorado. São Paulo: Faculdade de Arquitetura e Urbanismo da Universidade de São Paulo, 2003.

ARAUJO, R. A. D Caracterização dos materiais construtivos tradicionais em Pernambuco e Paraíba Relatório Técnico, 2009.

BARRETO, P. T. Casas de Câmara e Cadeia. Revista do Patrimônio histórico e Artístico Nacional n.11, p.9-196. Rio de Janeiro: Ministério da Educação e Saúde, 1947.

EG\&G ORTEC Materials Analysis Division. X Ray Critical - Absorption and Emision Energies Chart. Califórnia, 1980.

MARENGO, E.; ACETO, M.; ROBOTTI, E.; LIPAROTA, M. C. ; BOBBA, M.; PANTÒ, G. Archaeometric characterisation of ancient pottery belonging to the archaeological site of Novalesa Abbey (Piedmont - Italy) by ICP-MS and spectroscopic techniques coupled to multivariate statistical tools. Analytica Chimica Acta, v.537, p.359$375,2005$.

SOPKO, J. S.; MCEVOY, J. E. X-ray fluorescence analysis of 17th- and 18th-century brick samples from New York State. In: New York State Parks Recreation and Historic Preservation, Nova York, 1991.

TEIXEIRA, S. R.; SOUZA, S. A.; MOURA, C. A. I. Mineralogical characterization of clays used in the structural ceramic industry in west of S. Paulo State, Brasil. Cerâmica, v.47, n.304, p.204 -207, 2004. 